\title{
Risk Assessment on Operating Tunnels of High-Speed Railway in Perilous and Mountainous Area
}

\author{
Yunhao Yao* and Yuanfu Li
}

\author{
Southwest Jiaotong University Civil Engineering School, Sichuan Province Chengdu 610031, China
}

\begin{abstract}
The project named "the rescue system and key technology of high-speed railway in perilous mountains" primarily focuses on current railway constructions and operations in China. To state the relationship between risk events and risk factors, we classified the risk sources of operating tunnels of high-speed railway in perilous and mountainous area and established a hierarchical assessment system by using the example of high-speed railway from Guangzhou to Guiyang. According to the risk acceptance criteria and risk level standard, we analyzed the risks of operating tunnels qualitatively and quantitatively by using AHP-Fuzzy method. As a result, the key risks were characterized and proposals were listed. Our study provides a framework for the risk analysis and management of operating tunnels of high-speed railway in perilous and mountainous area.
\end{abstract}

Keywords: AHP-fuzzy theory, perilous and mountainous area, risks in operational period, tunnels of high-speed railway.

\section{INTRODUCTION}

In the past decades, high-speed railway construction has made tremendous progresses in China. Due to the complex terrain in southwestern China, there are many challenges for railway constructions and operations. One of the typical examples is the high-speed railway from Guangzhou to Guiyang, which serves as an important connection between southwest China and the south coast of China. The total length of the railway is $833.3 \mathrm{~km}$ with 212 tunnels consisting of about $55.9 \%$ of the overall length. It also locates at a region that suffers high frequency geographical hazards such as earthquake and other disasters caused by the complex geological structures.

After the "7-23" incident in 2012, risk management of high-speed railway has become a crucial topic not only for researchers, but also for the public. Since the construction of the high-speed railway from Guangzhou to Guiyang will be completed, the risk management of this railway will become focus at the operational stage.

Currently, the main guideline of risk management is "The Temporary Provisions about Risk Analysis and Management of Railway Tunnels", which focuses on the assessment of tunnels at the design and operational stages [1]. However, the assessment of tunnels at the operational stage is not clarified in this guideline. Taking the features of high-speed railways into accounts, such as fast objectives, the huge hazard of rescue, the complex surroundings and high rates of tunnels, we classified risk sources and established an assessment system for risks of operating tunnels of high-speed railways in perilous and mountainous area. We took the high-speed railway from Guangzhou to Guiyang as example, and analyzed the risks of the operating tunnels using AHPFuzzy method qualitatively and quantitatively.

\section{RISK ASSESSMENT ON HIGH-SPEED RAILWAY TUNNEL AT THE OPERATING STAGE}

\subsection{Risk Definition}

Risks of high-speed railway tunnels at the operating stage are defined as a combination of frequency and consequences of potential incidents, which consist of property losses, environmental damages, economic losses and construction delays.

\subsection{Risk Identification}

We identified all the potential risk sources which affect the operating tunnels of high speed railway in perilous and mountainous areas and listed risk factors which have profound effects on operating tunnels (Table 1). To further confirm and classify the risk factors (risk incidents), we divided each risk assessment units to corresponding subunits (Table 1).

\subsection{Risk Estimation}

To estimate the probability and consequences of the identified risk factors, risk probability distribution and the loss types and scales was given by using AHP-Fuzzy method [2-6].

\subsection{Risk Assessment}

Currently, assessment matrix and risk acceptance criteria are well accepted for evaluating the risk. Based on the risk estimation results and risk level standards described in "The Temporary Provisions about Risk Analysis and Management of Railway Tunnels", we defined the risk severity and its specific level. Accordingly, we also proposed a risk response strategy. 


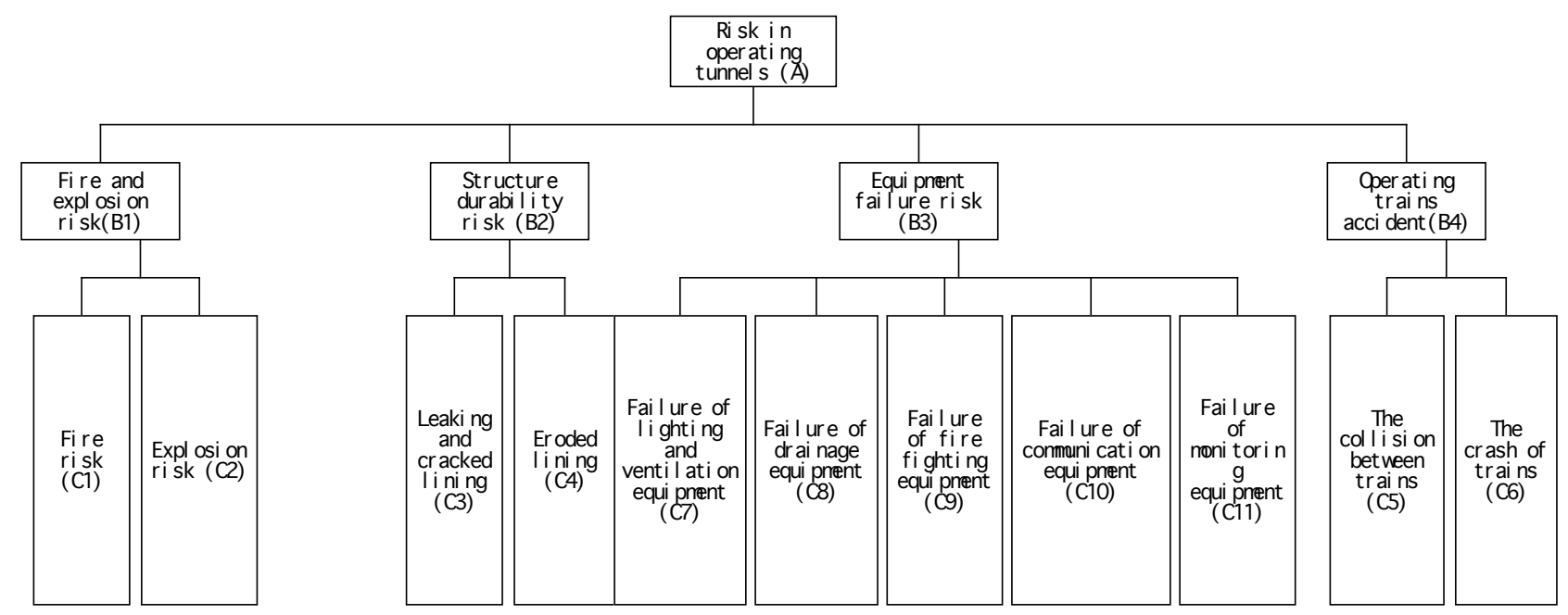

Fig. (1). Hierarchical structure of risk incident layers.

\section{RESEARCH OF RISK ASSESSMENT ON OPERAT- ING TUNNELS OF HIGH-SPEED RAILWAYS IN THE PERILOUS AND MOUNTAINOUS AREA}

According to the risk definition and criteria mentioned above, we determined the risk sources and categories, and established an index for risk assessment. The index shows the relationship between risk factors and risk incidents of high-speed railway tunnels at operational stage.

\subsection{Risk Incidents}

Based on the public data, the risks of high-speed railway tunnels at the operating stage could be divided into five types of risk incidents, including the risk of fire and explosion in tunnels, the risk of structure durability in tunnels, the risk of equipment failure and the risk of operation accident. Each type of incident was considered as the primary level of incidents and was further divided into sub-risk incidents by using AHP method. The hierarchical structure of risk incidents was illustrated in Fig. (1).

\subsection{Risk Factors}

Risk factors of operating tunnels of high-speed railway in perilous and mountainous area also consist of three primary types (Infrastructure, external environment and artificial damage).

\subsubsection{Risk Factors from Infrastructure}

Risks from the infrastructure factor contain civil infrastructure risk and operating equipment risk. Civil infrastructure could be affected by cracked lining, leaking lining and eroded lining, while operating equipment risks are mainly cause by failures of equipment that is designed for ventilation, lighting, firefighting, communication, monitoring, waterproof and drainage.

\subsubsection{Risk Factors from External Environment}

Risk factors from External environment comprise meteorological disaster, geological hazard and earthquake. Typhoon, rainstorm, high and low temperature, heavy fog, thunderstorm, gale, sand storm, hail snow are all considered as risk facts of meteorological disaster [7]. Collapse, landslide, land subsidence, ground fissure, water and mud bursting, debris flow, falling rock at tunnel portal are all accounted as risk factors from geological disaster. The last major risk factor is seismic risk factors which are primary caused by earthquakes or secondary effects from earthquakes.

\subsubsection{Risk Factors from Artificial Damage}

Risk factors from artificial damages contain factors such as the risk of a war, the risk of management, the risk of terrorist attack, the legacy risk of design and construction, and so on [8]. For instances, loopholes of management may come from organization settings, regulations, team spirit, professional quality, education, emergency measures and the effectiveness of decision [9, 10]. As a terrorist attack, it could be an explosive attack, an incendiary attack, a biochemical attack or a kinetic energy attacks. The legacy risk of design and construction could be consequences from noncomprehensive design, mistakes in designs, poor quality of constructions.

As a brief summary, risk incidents and risk factors taken accounted in our assessment system are listed in Table $\mathbf{1 .}$

\section{THE RISK ANALYSIS ON OPERATING TUNNELS OF HIGH-SPEED RAILWAY IN PERILOUS MOUN- TAINS BASED ON AHP-FUZZY THEORY}

\subsection{Comprehensive Assessment on the Second Level of Risk Incidents based on AHP-Fuzzy Theory}

To quantitatively assess the risks of operating tunnels of Guangzhou-Guiyang high-speed railway, we applied the AHP-Fuzzy method to analyze the risk incidents categorized in the third level of risk incident to evaluate the risk incident of the second level (Fig. 1) [11].

\subsubsection{Comment Sets and Factor Sets}

Comment sets contain probability assessment sets and consequence assessment sets.

The probability assessment set $=$ \{extremely possible, possible, occasionally, impossible, extremely impossible 
Table 1. Index of risk assessments.

\begin{tabular}{|c|c|c|}
\hline Risk Incident & The Type of Risk Factors & Risk Factors \\
\hline \multirow{9}{*}{$\begin{array}{c}\text { Fire and Explosion Risk } \\
\text { Structure Durability Risk } \\
\text { Operating Equipment Risk } \\
\text { Operating Train’s Accident Risk }\end{array}$} & \multirow{3}{*}{ External Environment Risk } & Meteorological Disaster \\
\hline & & Geological Disaster \\
\hline & & Earthquake \\
\hline & \multirow{6}{*}{ Artificial Damage Risk } & War \\
\hline & & Terrorist Attack \\
\hline & & Management Risk \\
\hline & & The Legacy Risk of Design and Construction \\
\hline & & Human Error \\
\hline & & The Quality of Material and Equipment \\
\hline
\end{tabular}

The Consequence assessment set $=$ \{catastrophic, very serious, serious, less serious, light $\}$

Factor sets are fire $(C 1)$, explosion $(C 2)$, cracked lining $(C 3)$, eroded lining $(C 4)$, the collision between trains $(C 5)$, trains crash $(C 6)$, ventilation lighting equipment fault $(C 7)$, waterproof and drainage equipment failure $(C 8)$, firefighting equipment fault $(\mathrm{C9})$, communication equipment fault $(\mathrm{ClO})$, monitoring equipment fault (C11).

\subsubsection{Determination of the Weight Vector}

The hierarchical structure (Fig. 1) was set up based on AHP method. The "probability vector" and "consequence vector" were acquired by using characteristic roots and consistency test.

"Probability weight vector"

$W_{P B 1}=(0.8333,0.1667) ; \quad W_{P B 2}=(0.6667,0.3333) ;$ $W_{P B 3}=(0.1429,0.8571) ; W_{P B 4}=(0.31,0.1791,0.2,0.2448$, and 0.0662).

$P B_{I}$ is denoted as the unit of risk incidents in the second level defined in Fig. (1).

"Consequence weight vector"

$W_{C B 1}=(0.7101,0.2899) ; \quad W_{C B 2}=(0.7101,0.2899) ;$ $W_{C B 3}=(0.8,0.2) ; W_{C B 4}=(0.2722,0.1285,0.4069,0.1030$, and 0.0894).

$C B_{1}$ is denoted as the unit of risk incidents in the second level defined in Fig. (1).

\subsubsection{Comprehensive Judgment}

To determine the fuzzy judgment matrix $R=\left(r_{i j}\right)_{m \times n}$ a function $f\left(u_{i}\right)$ was generated to judge each factor $u_{i}$, then a map called " $f$ " from $U$ to $V$ was established to induce a relationship called " $R_{f} \in F(U \times V)$ ".

Then we conduct a compound operation between $A$ and $R$ by using the model $M(*,+)$ to get the assessment on elements of risk incident on the second layer:

"Probability"

$$
\begin{aligned}
& \begin{array}{lllll}
0.3033 & 0.2883 & 0.2333 & 0.1583 & 0.0167
\end{array} \\
& R_{P B}^{1}=\begin{array}{ccccc}
0.3333 & 0.3167 & 0.2 & 0.1 & 0.05 \\
0.0971 & 0.1386 & 0.3413 & 0.3057 & 0.1029
\end{array} \\
& \begin{array}{llllll}
0.1427 & 0.2358 & 0.3057 & 0.1771 & 0.0694
\end{array}
\end{aligned}
$$

"Consequence"

$$
\begin{aligned}
& \begin{array}{lllll}
0.2145 & 0.4065 & 0.25 & 0.129 & 0
\end{array} \\
& R_{C B}^{1}=\begin{array}{ccccc}
0.0855 & 0.1355 & 0.2565 & 0.2645 & 0.258 \\
0.198 & 0.264 & 0.282 & 0.244 & 0.012
\end{array} \\
& \begin{array}{lllll}
0.1124 & 0.1804 & 0.2301 & 0.321 & 0.169
\end{array}
\end{aligned}
$$

A risk incident level and acceptance criteria were generated (Table 2). Therefore, we concluded that the highest risk incident level came from the fire and explosion risk, which was followed by the incident risks from the structure durability, and the operating equipment risk. The operating train accident was relatively small.

Therefore, in terms of the risk acceptance criteria table in "Contemporary Regulations on risk assessment and management of Railway Tunnels, the fire and explosion risk should catch the special attention during evaluation and preparation for the incidents of accidents, to avoid or at least reduce the risk to an undesired degree. For the tunnel structural risk and operating equipment risk failure, measurements must be taken to reduce the risk and enhance the monitoring. Finally, the train accident risk can be not a big cons relatively, but must be monitored.

Table 2. The evaluation of risk level.

\begin{tabular}{|c|c|c|}
\hline Risk Incident & Risk Level & Acceptance Criteria \\
\hline \hline Fire and explosion risk & Sky-high & Non-accept \\
\hline Structure durability risk & Very high & Non-expect \\
\hline Operating equipment risk & high & Non-expect \\
\hline Operating train accident & medium & accept \\
\hline
\end{tabular}




\subsection{Assessment of Risk Incidents on the Primary Level based on AHP-Fuzzy Method}

\subsubsection{Evaluation Set and the Factor Set}

Probability evaluation set $=\{$ probably, likely, occasionally, unlikely, impossible\}[12]

Consequences evaluation set $=\{$ catastrophic, very serious, serious, superior, minor\}

Factor sets are fire and explosion risk $\left(B_{l}\right)$, structure durability risk $\left(B_{2}\right)$, operating equipment risk $\left(B_{3}\right)$, Operating train accident $\left(B_{4}\right)$

\subsubsection{The Weight Vector of Risk Incidence on the Primary Level of Risk Incident}

"Probability weight vector":

$W_{P A}=(0.1358,0.3619,0.4355,0.0668)$

"Consequence weight vector":

$W_{C A}=(0.5536,0.1061,0.0513,0.2890)$

\subsubsection{AHP-Fuzzy Comprehensive Assessment}

We conducted the compound operation between " $A$ " and " $R$ ", by using the model $M(\bullet,+)$ and the results of comprehensive judgment on the second level of risk incidents.

Assessment result of "probability"

$\mathrm{R}_{\mathrm{PA}}=(0.2136,0.2299,0.2762,0.2026,0.0698)$

Assessment result of "consequence":

$R_{C A}=(0.1705,0.3051,0.2466,0.2048,0.0768)$

Based on the principle of maximal degree of membership and the evaluation results, we considered the probability of operating tunnels level as "occasionally" and consequences as "very serious". Therefore, according to the level of risk criteria we determine the risk level of the operating tunnels of high-speed railway in perilous and mountainous area as "high".

\subsection{Suggestions}

According to the results above, we proposed the following suggestions.

1) Establish an efficient operation mechanism and improve the responsibility mechanism $[13,14]$.

2) Set up reasonable refuges [15].

3) Increase the frequency of safety inspection to ensure hidden trouble could be handled immediately $[16,17]$.

4) Set up rescue guide signs for evacuation [18].

5) All high-speed trains should be equipped with adequate supplies for self-rescue, and disseminate self-rescue guide $[19,20]$.

\section{CONCLUSION AND LIMITATION}

In this paper, all possible identified risk events and risk factors was in accordance with the specific situations of the high-speed railway from Guiyang to Guangzhou, which was the whole base for our risk assessment on operating tunnels of high-speed railway in perilous and mountainous area. In addition, risk assessment and risk management are dynamic processes. Our evaluation model is also limited by currently technologies for equipment detections.

\section{CONFLICT OF INTEREST}

The authors confirm that this article content has no conflict of interest.

\section{ACKNOWLEDGEMENTS}

Declared none.

\section{REFERENCES}

[1] A. Haaek, "Current safety issues in traffic tunnels," Tunnelling and Underground Space Technology, vol. 17, no. 2, pp. 117-127, 2002

[2] F. Wang, and L.Y. Luo, "Probabilistic risk assessment of tunneling-induced damage to existing properties," Expert Systems with Applications, vol. 41, no. 4, pp. 951-961, 2014.

[3] Y. Abdolreza, "Proposing a new methodology based on fuzzy logic for tunnelling risk assessment," Journal of Civil Engineering and Management, vol. 20, no. 1, pp. 82-94, 2014.

[4] O. Spacková, E. Novotná, M. Šejnoha, and J. Šejnoha, "Probabilistic models for tunnel construction risk assessment," Advances in Engineering Software, vol. 62-63, pp. 72-84., 2013.

[5] K. Kazaras, K. Myrto, N. Zoe, and K. Konstantinos, "Enhancing road tunnel risk assessment with a fuzzy system based on the CREAM methodology," Chemical Engineering Transactions, vol. 31, pp. 349-354, 2013

[6] G. Zhou, "On risk assessment and management of frost damage in a tunnel located in a cold region based on ANP and fuzzy theory," Modern Tunnelling Technology, vol. 50, no. 1, pp. 60-66, 2013

[7] S. Li, S. Shi, L. Li, Z. Zhou, M. Guo, and T. Lei, "Attribute recognition model and its application of mountain tunnel collapse risk assessment," Journal of Basic Science and Engineering, vol. 21, no. 1, pp. 147-158, 2013

[8] J. A. Clarke, and D. F. Laefer, "Evaluation of risk assessment procedures for buildings adjacent to tunnelling works," Tunnelling and Underground Space Technology, vol. 40, pp. 333-342, 2014.

[9] S. Li, Z. Zhou, L. Li, Z. Xu, Q. Zhang, and S. Shi, "Risk assessment of water inrush in karst tunnels based on attribute synthetic evaluation system," Tunnelling and Underground Space Technology, vol. 38, pp. 50-58, 2013.

[10]. Z.Z. Wang, and Z. Zhang, "Seismic damage classification and risk assessment of mountain tunnels with a validation for the 2008 Wenchuan earthquake," Soil Dynamics and Earthquake Engineering, vol. 45, pp. 45-55, 2013.

[11] I. C. Cárdenas, S.S.H. Al-Jibouri, and J. I.M. Halman, "Modeling risk-related knowledge in tunneling projects," Risk Analysis, vol. 34, no. 2, pp. 323-339, 2014

[12] B. Liu, M. Shen, and Q. Ma, "Application of fuzzy analytic network process in risk analysis for construction of highway mountain tunnel. (Chinese)," Journal of Rock Mechanics and Engineering, vol. 33, no. 1, pp. 2861-2869, 2014

[13] X. Li, and Y. Li, "Research on risk assessment system for water inrush in the karst tunnel construction based on GIS: Case study on the diversion tunnel groups of the jinping II hydropower station," Tunnelling and Underground Space Technology, vol. 40, pp. 182$191,2014$.

[14] B. J. Arendsctal, "Evaluation of tunnel safety: towards an economic safety optimum. Reliability," Engineering and System Safety, vol. 90, pp. 217-228, 2005.

[15] I. C. Cárdenas, S. S.H. Al-jibouri, J. I. M. Halman, and T. F. A. Van, "Capturing and integrating knowledge for managing risks in tunnel works," Risk Analysis, vol. 33, no. 1, pp. 92-108, 2013.

[16] B. Liu, Y. Wang, and M. Niu, "Risk analysis and control in the Yellow River-crossing tunnel of South-to-North Water Diversion East Line," Applied Mechanics and Materials, vol. 357-360, pp. 2655-2658, 2013. 
[17] L. Hu, and T. Li, "Risk assessment of tunnel construction schedule and cost based on the alteration of rock mass classifications," Modern Tunnelling Technology, vol. 50, no. 6, pp. 39-43, 2013.

[18] J. Li, and X. Zhang, "AHP-based safety risk assessment and specialized design of a metro tunnel near a highway bridge," Modern Tunnelling Technology, vol. 50, no. 6, pp. 152-157, 2013.
[19] H. Bjelland, and T. Aven, "Treatment of uncertainty in risk assessments in the Rogfast road tunnel project," Safety Science, vol. 55, pp. 34-44, 2013.

[20] S. W. Agaiby, A. Schulter, U. Horny, O. Döllmann, and S. M. Ahmed, "Integration of design and risk management in large softground NATM tunnels," Geotechnical Special Publication, vol. 229, pp. 661-679, 2013.

Received: September 16, 2014

Revised: December 23, 2014

Accepted: December 31, 2014

(C) Yao and Li; Licensee Bentham Open.

This is an open access article licensed under the terms of the Creative Commons Attribution Non-Commercial License (http://creativecommons.org/licenses/by-nc/3.0/) which permits unrestricted, non-commercial use, distribution and reproduction in any medium, provided the work is properly cited. 